\title{
РАСЧЕТЫ ДИНАМИЧЕСКИХ РЕЖИМОВ РАБОТЫ ЭЛЕКТРОПРИВОДОВ САМОХОДНЫХ ГОРНЫХ МАШИН
}

\section{Е.К.ЕЩИН}

Кузбасский государственный технический университет имени Т.Ф.Горбачева, Кемерово, Россия

Рассмотрена задача совершенствования расчетов динамических режимов электроприводов самоходных горных машин, в частности, проходческих комбайнов. Обращается внимание на возможность в динамических режимах работы пространственного изменения положения корпуса статора асинхронного электродвигателя, входящего в состав электропривода, вокруг оси его ротора из-за конечной жесткости опор горной машины. В связи с этим возможны изменения абсолютной угловой скорости вращения электромагнитного поля статора этого электродвигателя. Отмечена необходимость введения в существующие математические модели, определяющие состояние и поведение асинхронных электродвигателей, дополнительных дифференциальных и алгебраических связей для вычисления абсолютной скорости электромагнитного поля статора и характера движения корпуса статора электродвигателя как части конструкции горной машины. Приведены результаты расчетов режима пуска вхолостую электродвигателя электропривода исполнительного органа проходческого комбайна, показывающие отличие характера изменения его электромагнитного момента, скорости вращения ротора, а также усилий в отдельных элементах редуктора исполнительного органа проходческого комбайна при движении корпуса статора от аналогичных результатов расчетов без учета движения корпуса статора. Сделан вывод о возможном расхождении расчетных и экспериментальных результатов при исследовании динамических режимов самоходных горных машин.

Ключевые слова: электропривод; статор электродвигателя; абсолютная скорость электромагнитного поля; динамические режимы работы

Как цитировать эту статью: Ещин Е.К. Расчеты динамических режимов работы электроприводов самоходных горных машин // Записки Горного института. 2018. Т. 233. C. 534-538. DOI: 10.31897/PMI.2018.5.534

Введение. Горные машины (ГМ) обычно делят на две группы: машины, которые не изменяют своего положения в пространстве - стационарные, и машины, работа которых принципиально связана с изменениями в пространстве положения их корпусов (ГОСТ Р 54976-2012. Оборудование горно-шахтное. Термины и определения) - самоходные, например, проходческие комбайны. К самоходным также можно отнести очистные комбайны с встроенной системой подачи. Электроприводы этих машин составляют единое целое с их корпусами и при всяком пространственном изменении также изменяются. В первую очередь это относится к пространственному изменению статоров асинхронных электродвигателей (АД) относительно продольных осей их роторов. АД являются основными электромеханическими преобразовательными устройствами электроприводов самоходных ГМ. Эти изменения могут оцениваться угловой скоростью корпуса статора АД ( $\omega_{s t}$ на рис.1), которая алгебраически суммируется с переносной синхронной скоростью вращения поля статора $\omega_{\text {п }}$ и образует абсолютную скорость вращения электромагнитного поля статора $\omega_{\text {абс }}=\omega_{\Pi} \pm \omega_{s t}$.

При работе с изменяющейся нагрузкой на исполнительном органе СГМ изменение угловой скорости корпуса статора АД по результату действия эквивалентно введению в цепь питания статора преобразователя частоты. При этом известно, что даже малые изменения частоты питающего напряжения могут привести к существенному изменению динамического состояния электромеханической системы ГМ [3].

Увеличение мгновенного значения скорости вращения поля статора $\omega_{\text {абс }}=\omega_{\text {п }} \pm \omega_{s t}$ при неизменных условиях питания приведет к снижению мгновенного значения электромагнитного момента, развиваемого АД. Снижение мгновенного значения скорости вращения поля статора обеспечит рост перегрузочной способности и увеличение мгновенного значения электромагнитного момента двигателя.

Возникающий электромагнитный момент АД при его пуске способствует возникновению колебательных вращательных движений вокруг оси ротора жестко незакрепленного статора, которые, в свою очередь, обеспечивают изменение абсолютной электрической скорости вращения электромагнитного поля статора и породившего эти процессы электромагнитного момента. Происходит качественная и количественная деформация характера изменения электромагнитного момента, развиваемого двигателем. Изменяется воздействие со стороны АД на механическое передаточное устройство (МПУ) - редуктор. 
При исследовании состояния АД обычно используется теория описания переходных процессов в электромеханических преобразователях, которая ориентирована на неподвижный статор электродвигателя [2, 5, 6, 8, 11-16], например [2, c. $9 ; 8$, c.52; 15 , с. 81$])$, и не учитывает изменения возможных изменений электромагнитного момента АД из-за пространственных движений статора.

Таким образом, вопросы формирования электромагнитных моментов асинхронных электродвигателей с жестко незакрепленным статором в достаточной мере не изучены. Уточнение влияния возможных изменений скорости вращения поля статора из-за его жесткой незакрепленности на характеристики АД - актуально и значимо для целого ряда электроприводов ГМ [10].

Постановка проблемы. Понятно, что естественным путем уточнения влияния возможных изменений абсолютной скорости вращения электромагнитного поля статора АД в динамических режимах работы является определение правил формирования в математических моделях АД

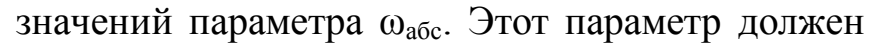
явно присутствовать в модели АД. Отсюда возникает проблема дополнения математической и компьютерной моделей АД уравнениями и реализующими их блоками, определяющими возможные движения корпуса статора АД и значения абсолютной скорости вращения электромагнитного поля статора - параметра $\omega_{\text {абс. }}$ В результате появляется возможность уточнения расчетов электромагнитных состояний АД и механических компонентов электропривода ГМ в динамических режимах работы.

Методология. Рассмотрим решение задачи на конкретном примере электропривода исполнительного органа проходческого комбайна КСП-32 [7]. Кинематическая схема приведена на рис.2. Исходную математическую модель АД примем с обозначениями [6, с.493]:

$$
\left\{\begin{array}{l}
\boldsymbol{U}_{s}=R_{s} \boldsymbol{I}_{s}+\frac{d \boldsymbol{\Psi}_{s}}{d t}+j \omega_{k} \boldsymbol{\Psi}_{s}, \\
\boldsymbol{U}_{r}=R_{r} \boldsymbol{I}_{r}+\frac{d \boldsymbol{\Psi}_{r}}{d t}+j\left(\omega_{k}-p \omega\right) \boldsymbol{\Psi}_{r},
\end{array}\right.
$$

где $\boldsymbol{U}_{s}, \boldsymbol{U}_{r}$ - векторы напряжений питания статорной и роторной обмоток; $\boldsymbol{I}_{s}, \boldsymbol{I}_{r}-$ векторы токов статора и ротора; $\boldsymbol{\Psi}_{s}, \boldsymbol{\Psi}_{r}-$ векторы потокосцеплений статора и ротора; $\omega_{k}-$ скорость вращения координатной системы; $\omega$ - геометрическая скорость вращения ротора; $p$ - число пар полюсов; $R_{s}, R_{r}$ - активные сопротивления обмоток статора и ротора.

Приведенная совокупность дифференциальных связей должна быть дополнена уравнениями движения, определяющими движения ротора и возможные движения корпуса статора АД:

$$
\left\{\begin{array}{l}
\frac{d \omega}{d t}=\frac{1}{J_{a d}}\left(M-M_{c a d}\right), \\
\frac{d \omega_{s t}}{d t}=\frac{1}{J_{s t}}\left(M-M_{y s t}\right), \\
\frac{d M_{y s t}}{d t}=c_{s t} \omega_{s t}+b_{s t} \frac{d \omega_{s t}}{d t},
\end{array}\right.
$$


где $\omega, \omega_{s t}-$ угловые скорости вращения ротора и корпуса статора АД; $M$ - электромагнитный момент АД; $M_{c a d}-$ момент сопротивления на валу АД; $J_{a d}$ - момент инерции АД; $J_{s t}$-момент инерции объединенных с корпусом АД частей $\Gamma \mathrm{M} ; M_{y s t}-$ упругий момент, возникающий в опорах ГМ при ее движении; $c_{s t}-$ жесткость (упругость) опор $\Gamma \mathrm{M} ; b_{s t}-$ коэффициент демпфирования колебаний (вязкости) в опорах.

Заметим, что движения корпуса статора АД определяются режимом его работы «на упор».

В синхронной системе координат $(u, v)$ абсолютная угловая скорость вращения электромагнитного поля статора определится алгебраической суммой угловых переносной $\left(\omega_{\text {н }}-\right.$ номинальная скорость вращения поля) и относительной $\left(\omega_{s t}\right)$ скоростей $-\omega_{\text {абс }}=\omega_{\mathrm{H}} \pm \omega_{s t}$.

В неподвижной системе координат $(\alpha, \beta) \omega_{\text {абс }}= \pm \omega_{s t}$. Знак перед $\omega_{s t}$ определяется режимом ускорения или торможения ротора АД и определяется по правилу $-\operatorname{sign}(d \omega / d t)$, т.е. в практических вычислениях абсолютная скорость электромагнитного поля статора определится как

$$
\left\{\begin{array}{l}
\omega_{\text {абос }}=\omega_{\mathrm{н}}-\omega_{s t} \operatorname{sign}(d \omega / d t)(u, v), \\
\omega_{\text {абос }}=-\omega_{s t} \operatorname{sign}(d \omega / d t)(\alpha, \beta) .
\end{array}\right.
$$

Реализация связей (1)-(3) в инструментальной среде Matlab/Simulink с учетом формирования нагрузки на валу АД по [4] для режима пуска АД прямым включением в питающую сеть без нагрузки позволила получить результаты, приведенные на рис.3-6. Отметим, что в этом режиме момент сопротивления на валу АД определяется последовательным подключением инерционных масс шестерен и зубчатых колес редуктора (см. рис.2).

Видно (рис.3), что учет возможных движений корпуса статора АД в режиме пуска приводит к существенному изменению формы зависимости электромагнитного момента $M$ во времени (1 на рис.3). Происходит существенный сдвиг «влево» относительно расчетной формы изменения $M$ без учета влияния движения корпуса статора АД. Последнее вполне объяснимо. При пуске АД возникает движение его корпуса, оцениваемое угловой скоростью статора $\omega_{s t}(5$ на рис.4). Оно практически всегда может быть зафиксировано как небольшой «толчок», который ощущается даже без использования специальной регистрирующей аппаратуры.

Максимальное значение (в приводимом примере) $\omega_{s t}$ равно 0,09 о.е. (при $t \approx 0,1$ с) или $14,13 \mathrm{c}^{-1}$. Эти, сравнительно небольшие, изменения $\omega_{s t}$ повлекут за собой снижение абсолютной величины скорости вращения электромагнитного поля статора $\omega_{\text {абс }}$ (в максимуме $\omega_{s t}$ до $143 \mathrm{c}^{-1}$

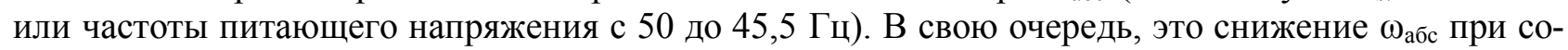
хранении амплитуды питающего напряжения неизменным вызывает увеличение величины электромагнитного момента, что и приводит к существенным деформациям переменных состояния АД (2 в 1,4 в 3 на рис. $3 ; 2$ в 1,4 в 3 на рис. 4$)$.

Заметим, что изменение (снижение) амплитуды питающего напряжения АД в режиме пуска при питании АД от трансформаторной подстанции через кабельную сеть естественным образом снижает амплитудные значения момента $M$, однако практически сохраняет его качественную форму (кривая 5 на рис.3).

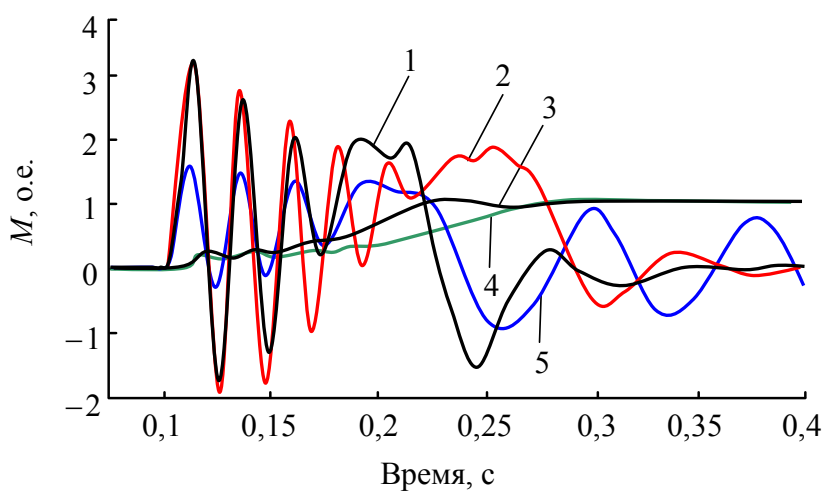

Рис.3. Характер изменения электромагнитного момента АД $(1,2,5)$ и его скорости $(3,4)$ с учетом $(1,3)$ и без учета $(2,4)$ движений корпуса статора в режиме пуска, 5 - при питании через кабель

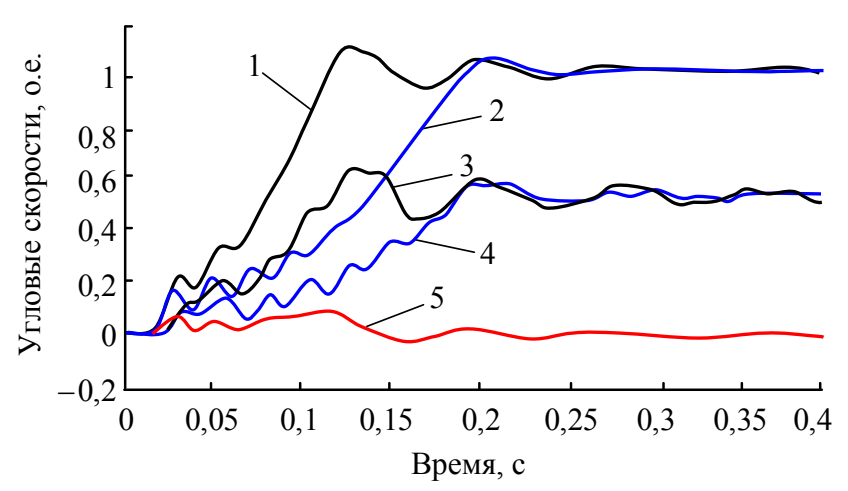

Рис.4. Изменение угловой скорости ротора АД $(1,2)$, зубчатого колеса 4 (2, 3 на рис.2) и угловой скорости корпуса статора $\omega_{s t}(5)$ при учете $(1,3)$ и без учета $(2,4)$ движений корпуса статора в режиме пуска 


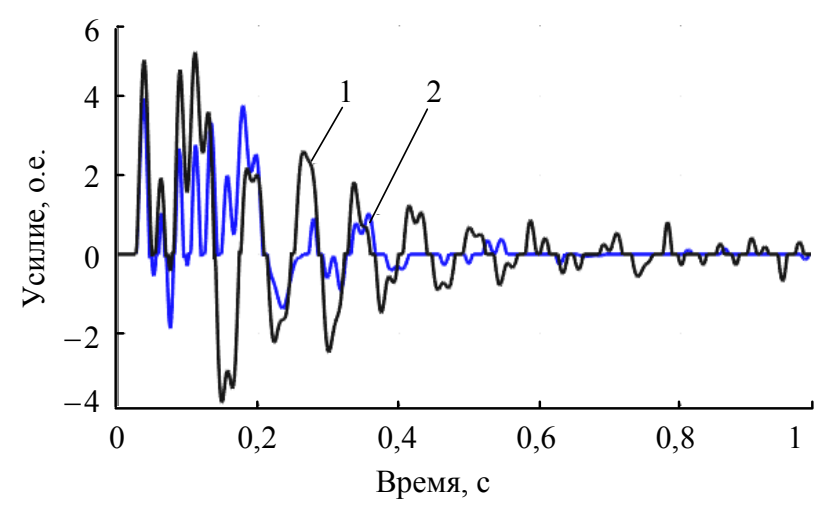

Рис.5. Изменение усилия в зацеплении шестерни и зубчатого колеса $(1,2$ на рис. 2$)$ при учете (1) и без учета (2) движений корпуса статора АД в режиме пуска

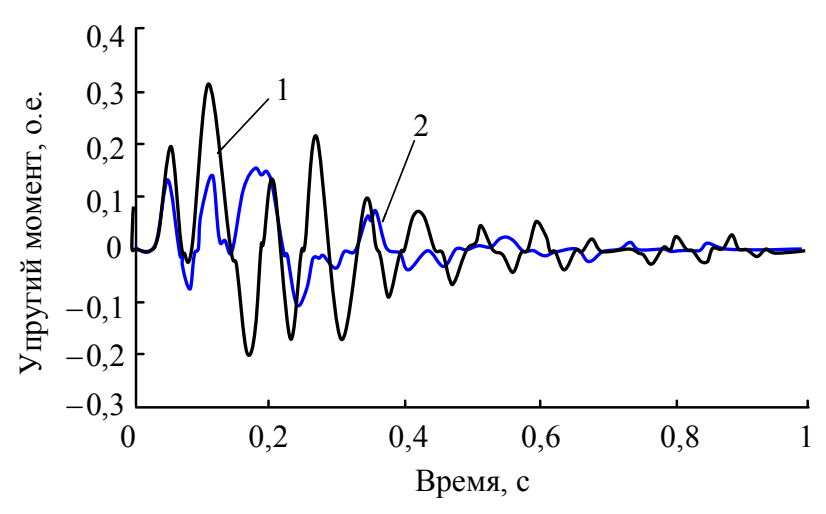

Рис.6. Изменение упругого момента вала (3 на рис.2) при учете (1) и без учета (2) движений корпуса статора АД в режиме пуска

Изменение усилия в зацеплении шестерни и зубчатого колеса (1, 2 на рис.2), а также изменение упругого момента вала (3 на рис.2) иллюстрируют изменение состояния отдельных элементов механического передаточного устройства (редуктора) при учете подвижности корпуса статора АД. Можно отметить, что происходит увеличение пиковых значений усилий и упругого момента, что является следствием увеличения значений электромагнитного момента АД.

Расчетная сравнительная практика при учете возможных движений корпуса статора АД (рис.3-6) показывает их существенное влияние на динамическое состояние АД и далее на процессы в МПУ (редукторе). Движение корпуса статора АД подтверждает чрезвычайную чувствительность характеристик АД к изменению частоты питающего напряжения $[1,9]$.

Таким образом, практическая значимость работы заключается в возможности повышения достоверности расчетной оценки состояния электропривода самоходных горных машин в динамических режимах работы.

Выводы. При исследовании динамических режимов работы электроприводов самоходных ГМ проблематично использование классической теории описания состояния асинхронного электродвигателя из-за допущения в ней неподвижности статора электрической машины. Подвижность корпуса статора АД, возникающая из-за технологических особенностей работы СГМ, приводит к изменению абсолютной угловой скорости вращения электромагнитного поля статора АД, что, как известно, равносильно изменению характеристик АД путем изменения частоты питающего напряжения. Последнее влечет за собой возникающую неконтролируемую погрешность расчетов и возможное необъяснимое расхождение результатов экспериментов и теоретических расчетов при выполнении исследовательских работ с реальными электроприводами самоходных горных машин.

\section{ЛИТЕРАТУРА}

1. Булгаков А.А. Частотное управление асинхронными двигателями. М.: Энергоиздат, 1982. 216 с.

2. Горев А.А. Переходные процессы синхронной машины. М.-Л.: Госэнергоиздат, 1950. 551 с.

3. Ещин E.K. Вариант частотного управления асинхронным электроприводом горных машин // Электротехника. 1996. № 1. C. 28-30.

4. Ещин Е.К. Детализация расчетов динамических режимов работы электроприводов горных машин // Горное оборудование и электромеханика. 2017. № 5. С. 35-39.

5. Ключев В.И. Теория электропривода. М.: Энергоатомиздат, 2001. 704 с.

6. Ковач К.П. Переходные процессы в машинах переменного тока / К.П.Ковач, И.Рац. М.-Л.: Госэнергоиздат, $1963.744 \mathrm{c}$.

7. Комбайн проходческий КСП-32. Руководство по эксплуатации / В.Т.Антипов, Н.С.Тапехин, Е.С.Серов, В.А.Гафанович; АО «Ясиноватский машиностроительный завод». 1999. Кн. 1. 119 c. // https://www.twipx.com/file/22907/

8. Копылов И.П. Электромеханические преобразователи энергии. М.: Энергия, 1973. 400 с.

9. Костенко М.П. Работа многофазного асинхронного двигателя при переменном числе периодов // Электричество. 1925. № 2. С. 85-95.

10. Обеспечение устойчивости проходческого комбайна с двухкорончатым реверсивным рабочим органом / А.А.Хорешок, Л.Е.Маметьев, А.М.Цехин, А.Ю.Борисов // Горное оборудование и электромеханика. 2016. № 6. С. 3-7. 
Расчеты динамических режимов работы электроприводов...

11. Dieter Gerling. Electrical Machines. Mathematical Fundamentals of Machine Topologies. New York: Springer, 2015. P. 472.

12. Jan A. Melkebeek. Electrical Machines and Drives. Fundamentals and Advanced Modelling. Cham (Switzerland): Springer International Publishing AG, 2018. P.442.

13. Juha Pyrhőnen. Design of rotating electrical machines / Juha Pyrhőnen, Tapani Jokinen, Valéria Hrabovcová. Chichester (United Kingdom), John Wiley \& Sons, Ltd., 2008. P.512.

14. Lyshevski S.E. Electromechanical systems and devices. New York: Taylor \& Francis Group, 2008. P.565.

15. Park R.H. Two-Reaction Theory of Synchronous Machines. Generalized Method of Analysis - Part I // Transactions of the American Institute of Electrical Engineers. 1929. Vol. 48. Iss. 3. P. 716-727.

16. Sen P.C. Principles of electric machines and power electronics. Chennai (India): John Wiley \& Sons, Inc., 2014. P.618.

Автор Ещин Е.К., д-р техн. наук, профессор, eke_kuzstu@таil.ru (Кузбасский государственный технический университет им. Т.Ф.Горбачева, Кемерово, Россия).

Статья поступила в редакиию 16.03.2018.

Статья принята к публикачии 21.06.2018. 